\title{
Spore Concentrations in the Atmosphere at Ahmadi, a New Town in Kuwait
}

\author{
By R. R. DAVIES \\ The Wright-Fleming Institute of Microbiology, \\ St Mary's Hospital Medical School, London, W.2
}

(Accepted for publication 13 November 1968)

\begin{abstract}
SUMMARY
The fungal air spora and the microfungi in house dust are described. Pollens from indigenous weeds of the Chenopodiaceae which were deliberately planted in the area were most numerous, that from the introduced trees of Prosopis spicigera (an important allergen) was trapped only sporadically at roof-top level, but found in high concentration beneath the trees. Low Cladosporium counts in the hot season are related to degree-days above $29^{\circ}$. The origins of the spora and the possibility of dust being colonized by fungi in air-cooled houses is discussed. Since inhalant allergy is likely to increase among the population as planting programmes extend the areas of vegetative cover in this hot arid region, future surveys on the air spora are desirable.
\end{abstract}

\section{INTRODUCTION}

The air spora in areas where vegetative cover is sparce or entirely absent has been studied by a number of workers. Pady \& Kapica (1953) and Polunin (1955) have examined air samples from Arctic regions. The content of the air at Tucson, in the shrub and cactus-covered landscape of the Sonoran desert of Arizona has been briefly described by Dworin (I967). Wilkinson (1964) has produced a pollen calendar for Ahmadi which lies in the area described by Blatter (1919) as the extra-tropical desert of Arabia. Dworin reported a two-peak curve for the occurrence of airborne pollen, one in the spring and one in the autumn, and Wilkinson reported a similar curve for the incidence of hay fever. The sampling technique used by Dworin was not described but that used to study airborne pollen by Polunin and by Wilkinson was the horizontally exposed sticky slide which Gregory \& Stedman (1953) have shown to have serious defects as a quantitative method for sampling such particles outdoors. Nevertheless, pollen grains in the air of the Arctic and hot desert areas have been demonstrated. The present study describes observations on the concentrations in which pollens and fungal spores occur in the air at Ahmadi and discusses their origins and relevance to the development of inhalant allergy in the population.

The establishment of a town at Ahmadi on the Persian Gulf, some $36 \mathrm{~km}$. south of the state capital of Kuwait, commenced in 1946. Since then the town has been developed into a suburb-like district of tree-lined streets and houses with lawns and gardens. Wilkinson (1964) reported that among the trees planted in an area of $6 \mathrm{~km}^{2}$ there were 10,000 Prosopis spicigera Linn., 10,000 Tamarisk, 6000 Eucalyptus, 2500 Parkinsonia, I500 Albizzia and many thousands of shrubs such as Oleander and flowering currant. An even more extensive planting programme has been adopted in the state capital, Kuwait. 


\section{METHODS}

A spore trap (Hirst, 1952), which is volumetric and continuously recording, was set up on the flat roof of the company store in central Ahmadi. The methods used were as described by Davies, Denny \& Newton (1963) except that silicone grease, dissolved in chloroform for ease of application, although optically inferior to petroleum jelly, replaced petroleum jelly because of the very high summer temperatures. The greased slides, prepared in this laboratory and sent to Kuwait in polythene staining jars with screw caps, were exposed for $24 \mathrm{hr}$ every 2 or 3 days between August 1962 and March 1963, and, after exposure, returned to London and mounted in glycerol jelly. They were scanned as previously described (Davies et al. 1963) and the mean concentration for the pollen and spores trapped was calculated. The amount of sand trapped made scanning difficult and the deposits obtained during sandstorms were useless: sand tends to obscure small spores already trapped and, when airborne in high concentrations, quickly decreases the area of adhesive surface and consequently the retentivity of the slide. The concentrations of pollens and spores described therefore tend to be underestimates.

\section{RESULTS AND DISCUSSION}

Pollen. During the period studied pollen of the Chenopodiaceae was predominant, forming $66 \%$ of the total pollen catch (Fig. $x$ ). The maximum concentration recorded on any one day was 140 grains $/ \mathrm{m}^{3}$ on 6 October. Catches could not be correlated with any particular wind direction.

Grass pollen accounted for $3 \%$ of the pollen trapped, it occurred sporadically in the air between August and the end of October and the highest concentration recorded was Io grains $/ \mathrm{m}^{3}$

The pollen of Prosopis was trapped on four occasions only: Io grains $/ \mathrm{m}^{3}$ on 10 September and 24 November and 5 grains $\mathrm{m}^{3}$ on 28 November and 4 December. Between the beginning of August and the end of October pollens similar to those of Artemisia, Betula, Platanus, the Rosaceae and Umbelliferae were occasionally trapped, and they together comprised $3 \%$ of the entire pollen catch. Artemisia was the most common and reached a maximum concentration of 20 grains $/ \mathrm{m}^{3}$

About $28 \%$ of the pollens in the deposits were not identified, partly through unfamiliarity with the local plants, but mainly because many of the grains were damaged, some showing conspicuous holes. Damaged pollen grains have not been a conspicuous feature in deposits obtained from the air of European cities and the damage may be attributed to the effect of attrition by wind-blown sand.

Fungal spores. The most common fungal spores were those of the genus Cladosporium; they occurred throughout the period sampled and their maximum daily concentration was $\mathrm{I} 725$ spores $/ \mathrm{m}^{3}$ on 28 November. They formed $66 \%$ of the total fungal spores (Fig. 2). The highest concentrations of Cladosporium and total fungal spores were obtained when the wind was from the N.W. sector.

Ustilago spores were next in frequency; average monthly concentrations with those for some of the other spore types commonly trapped are given in Table I.

Among the more rarely encountered spores were: Aspergillaceae, Botrytis, Chaetomium, Curvularia, Epicoccum, Erysiphe, Ganoderma, Leptosphaeria, Monotospora, 
Mucoraceae, Pleospora, Polythrinicium, Pullularia, Sordaria, rust uredospores and teleutospores, Tilletia, Trichothecium and brown ascospores morphologically similar to Venturia. There were also dematiaceous spores which, through unfamiliarity and because they could not be removed from the slides and grown in culture, were not identified.

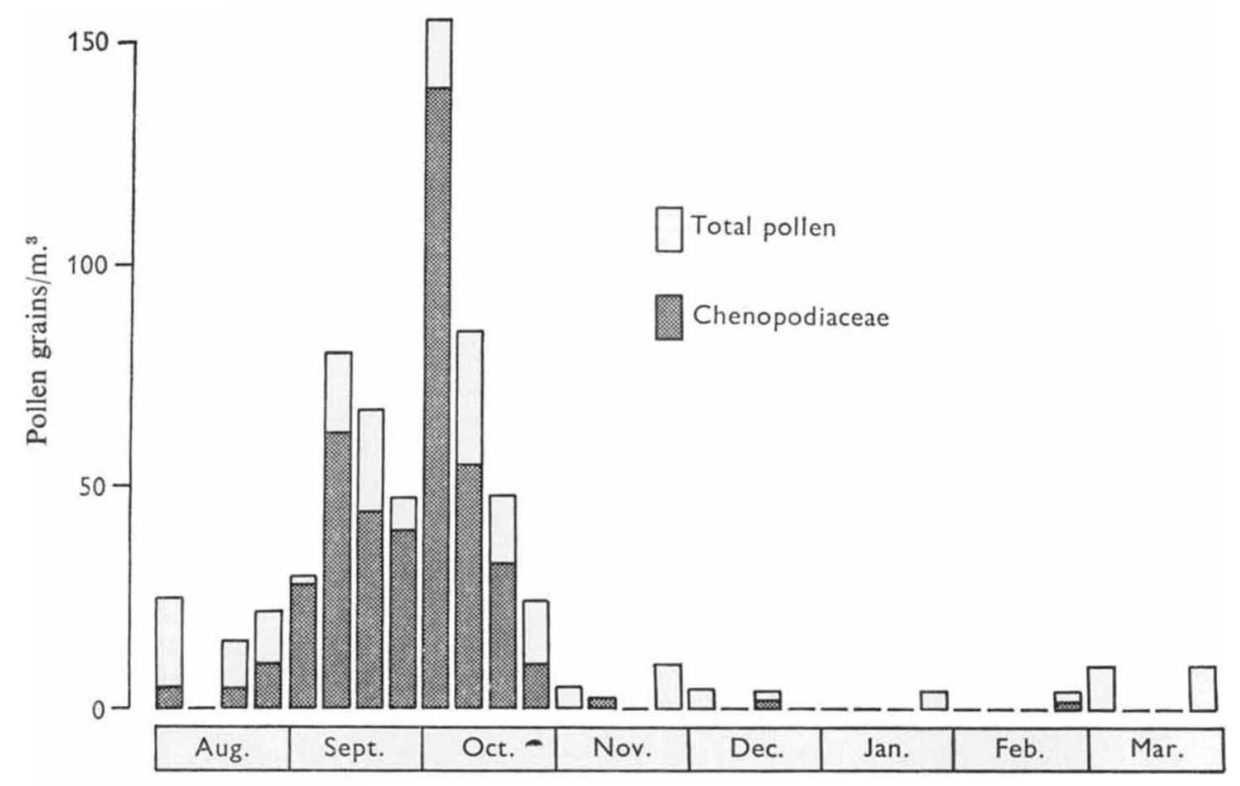

Fig. 1. Weekly average concentration for pollens of the Chenopodiaceae in relation to the total pollen catch.

Table I. Airborne spore concentrations at Ahmadi

\begin{tabular}{|c|c|c|c|c|c|c|c|c|c|}
\hline \multirow[b]{2}{*}{ Spore } & \multirow{2}{*}{$\begin{array}{l}\% \text { of } \\
\text { total } \\
\text { spores }\end{array}$} & \multicolumn{8}{|c|}{ Average numbers $/ \mathrm{m} .{ }^{3} /$ month } \\
\hline & & Aug. & Sept. & Oct. & Nov. & Dec. & Jan. & Feb. & Mar. \\
\hline Ustilago & 8 & 95 & 106 & 4I & $3 I$ & 25 & 14 & I I & I7 \\
\hline Alternaria & 4 & 6 & I3 & II & 14 & 4 & 24 & I4 & 9 \\
\hline $\begin{array}{l}\text { Helmintho- } \\
\text { sporium }\end{array}$ & 3 & Io & 18 & 14 & $5 I$ & 3 & 6 & 6 & 4 \\
\hline Ascospores & 3 & 24 & I8 & IO & 6 & 24 & 14 & 12 & 13 \\
\hline Basidiospores & 4 & 12 & 22 & II & 57 & 26 & 12 & 4 & 6 \\
\hline $\begin{array}{l}\text { Hyaline } \\
\text { indeterminate } \\
\text { spores }\end{array}$ & 0.2 & 2 & I & 3 & 2 & I & 0 & 0 & 0 \\
\hline $\begin{array}{l}\text { Mycelial } \\
\text { fragments }\end{array}$ & 6 & 26 & 49 & 42 & 30 & 32 & 19 & 19 & 23 \\
\hline
\end{tabular}

On one of the exposed slides the conidiophore of Aspergillus terreus Thom with over 50 conidia attached was specifically identified and on another the whole sporangium of a Mucor packed with endospores.

Effect of climate on the air spora. The tropical desert of Arabia is hot in summer. Shade temperatures greater than $49^{\circ}$ were recorded and in August 1962 at Ahmadi the average shade temperatures were $44.4^{\circ}$ maximum and $29 \cdot 2^{\circ}$ minimum. Most fungi 
have an optimum temperature for development between $20^{\circ}$ and $24^{\circ}$ and do not grow above $29^{\circ}$. In temperate climates, where winter temperatures are too low for the growth of higher green plants, the values of 'Accumulated Temperature' above a base temperature of $5^{\circ}$, the minimum temperature at which plant development is sustained, has been of use to the ecologist and agricultural meteorologist. (It denotes the combined amount and duration of the excess or deficit of air temperature above or below

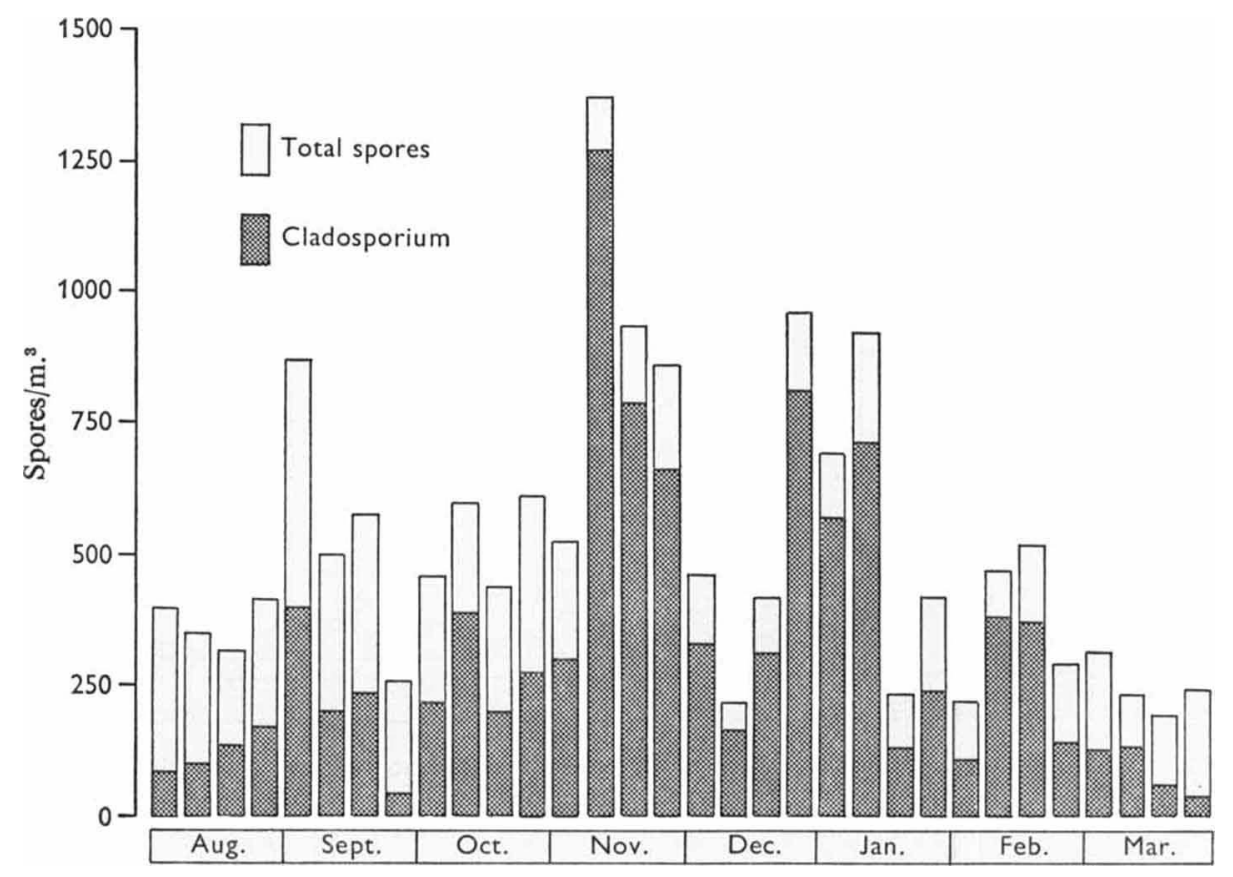

Fig. 2. Weekly average concentrations of Cladosporium in relation to the total spores trapped.

Table 2. Mean concentrations of chenopod pollen and Cladosporium spores with monthly values of accumulated temperature in degree-days below 29 and $20^{\circ}$

$\begin{array}{crrrrrr}\text { Month } & \text { Aug. } & \text { Sept. } & \text { Oct. } & \text { Nov. } & \text { Dec. } & \text { Jan. } \\ \begin{array}{c}\text { Accumulated } \\ \text { temp. below }\end{array} & 6 & 30 & 76 & 235 & 367 & 436 \\ 29^{\circ} & & & & & & \\ \begin{array}{c}\text { Accumulated } \\ \text { temp. below }\end{array} & 0 & 0 & 0 & 6 \text { I } & 105 & 167 \\ 20^{\circ} & & & & & & \\ \begin{array}{c}\text { Chenopod } \\ \text { pollen }\end{array} & 5 & 44 & 60 & \text { I } & \text { I } & 0 \\ \begin{array}{c}\text { Cladosporium } \\ \text { spores }\end{array} & 126 & 220 & 269 & 758 & 405 & 404\end{array}$

a base temperature. It is expressed in units of degree-days so that amounts for individual days can be added together to obtain the amount for all the days together.) Since shade temperatures in Kuwait during summer appeared too high for develop- 
ment of most fungi, the values of accumulated temperature below $29^{\circ}$ and below $20^{\circ}$ for each month during the period studied are given together with the mean concentrations for Cladosporium and chenopod pollen in Table 2.

Between August and November, as the monthly accumulated temperature below $29^{\circ}$ rose, the concentration of Cladosporium increased to its seasonal maximum in November. From November onwards, the accumulated temperatures below $20^{\circ}$ also increased, and the concentrations of Cladosporium then decreased, as does the rate of growth in artificial culture at incubation temperatures below $20^{\circ}$. The development of Cladosporium is not only limited by temperature butalso by the availability of moisture and moribund vegetation upon which it grows. Although during the period studied the relative humidity of the atmosphere increased from a mean of $49 \%$ in August to $61 \%$ in December, no rain fell before 8 November when the monthly total of $5 \mathrm{~mm}$. was precipitated on that day. The total rainfall for December was $4.4 \mathrm{~mm}$; $3.7 \mathrm{~mm}$. was recorded on the IIth and on only three other days was rain recorded.

Among the Cladosporium spores trapped in November and December were large clumps containing as many as 40 conidia, indicating production from a local source. Much of the Cladosporium trapped in August and September most probably had an origin in spore clouds developed to the N.W. of Kuwait in more temperate regions where cereals and grasses are grown. Evidence of spore transport into the area is also given by Ustilago; its monthly concentrations (Table I) were highest in August and September and then declined.

Chenopod pollen occurred from I August onwards and by the 25th reached 25 grains $/ \mathrm{m}^{3}$; the plants producing this pollen were clearly less inhibited by high temperature than Cladosporium and other fungi.

Viable moulds in house dust. The concentrations in which fungi occur in the indoor atmosphere in Kuwait are unknown but, when house dust was collected during the routine vaccum cleaning of two houses in Ahmadi, the following were isolated: Aspergillus niger, van Tieghem, A. flavus, Link, Neurospora sitophila, Shear and Dodge, Rhizopus arrhizus, Fischer, $R$. stolonifer (Ehrenb. ex Sar.) Lind., Ulocladium atrum Preuss. and Penicillium, Cladosporium, Helminthosporium and Stemphylium species.

Aspergillus niger was the most common mould in the samples examined and colony counts were from 3000 to $40,000 / \mathrm{g}$. dust. I also found $A$. niger to be the most common mould in dust from houses and the desert in Egypt.

Origins of the air spora at Ahmadi. When the development of the township was commenced the seeds of two indigenous plants, the salt bush Salsola baryosma (Roem. et Schult) Dandy and a thorny shrub Cornulaca leucacantha Charif et Aellen were sown in the area to bind the sand. Dickson (1955) reported Cornulaca as common near the sea shore and flowering in October, and Salsola as common in parts of the desert and flowering in May and September. Both these members of the Chenopodiaceae have spread in profusion (Wilkinson, 1964) although at present Salsola is the common weed in the uncultivated spaces and is the most likely source of the chenopod pollen.

The tree Prosopis spicigera Linn is a new introduction to the area and although it is reported to be an important source of airborne pollen by Wilkinson (1964), little was encountered in the Hirst trap deposits when it was flowering in November and December. These trees also flower in the spring, and when air was sampled with a rotorod (Perkins, 1957) beneath trees in April clumps of grains were trapped and a 
local concentration of 60 grains $/ \mathrm{m}^{3}$ was recorded. Since large clumps of pollen grains settle quickly to the ground it seems likely that Prosopis pollen occurs in high concentration only in the vicinity of the trees.

The source of the grass pollen lies in the lawns of Cynodon dactylon (Linn.) Pers. It is the only grass which will withstand the heat and it occurs naturally in the area. None of the other pollens trapped could be related to introduced plants and they seem to be of indigenous origin.

Ustilago and Leptosphaeria eustoma (Fries) Sacc. of the fungal spores appear to be borne into the area by the prevailing winds from more temperate cereal-growing areas (e.g. in Iraq to the N.W.). That there are local sources of spores is also evident. Dickson (1955) reported that toadstools, puff balls and the truffles Tirmania and Terfezia species occur in the desert and highest basidiospore concentrations were obtained in November when temperatures were optimal for fungal growth. The concentrations of Cladosporium rose as ambient temperatures declined from the extreme heat of the summer.

The mean concentration of Cladosporium in August and September of 178 spores $/ \mathrm{m}^{3}$ is similar to that of $132 / \mathrm{m}^{3}$ reported by Pady \& Kapica (1953) during the summer sampling at Churchill in the Arctic. At Churchill the tundra contributes to the air spora, in Kuwait, even when temperatures are inimical to the growth of Cladosporium, its spores may become airborne from fragments of vegetation and even whole plants uprooted and blown about the desert by the wind. Davies (I959) reported that Cladosporium conidia are detached from conidiophores by the impact of minute water droplets $(<0.2 \mathrm{~mm}$. diam.) in a moving mist or cloud, and Hirst \& Stedman (I963) reported that the collision of glass beads with deposits of Lycopodium spores disseminates the spores into the air. The effect of windblown sand will be similar and probably accounts for long lengths of hypha, conidiophores and the sporangium in the Ahmadi deposits. Damage to plant tissue by windblown sand is described by Rotem (1965).

Under mesophytic conditions such as prevail in Britain, hyaline conidia, hyaline ascospores, and Sporobolomyces and Tilletiopsis spores can become airborne in high concentration. Neither Sporobolomyces nor Tilletiopsis was trapped in Kuwait. It is usually assumed that hyaline spores are less adapted to withstand ultraviolet irradiation than dematiaceous ones and that the brown pigment confers protection. The sparcity of a hyaline spora in Kuwait is probably unrelated to ultraviolet irradiation since Sporobolomyces and Tilletiopsis grow and sporulate on the transpiring surfaces of leaves (Last, I955), on dorsiventral leaves growth is therefore confined to the shaded surfaces, and apart from the plants introduced and grown under irrigation in Kuwait, the flora is xerophytic with minimal transpiration.

Indoors at Ahmadi, where the air is cooled, moulds may colonize dust collected in the air ducts. In August 1962 the mean temperature outdoors was $37^{\circ}$ and the average relative humidity $49 \%$; if no water was removed in the air-conditioning equipment, lowering the temperature $10^{\circ}$ to $27^{\circ}$ would increase the relative humidity to $90 \%$ and cooling to $25^{\circ}$ would produce dew point. Davies (1960) reported that moulds such as Aspergillus repens develop in house dust at relative humidities as low as $75 \%$, many common moulds such as other Aspergillus species and the penicillia colonize house dust at relative humidities of $85 \%$ and Absidia and Mucor species develop when the humidity reaches $93.7 \%$. 
The air spora in relation to inhalant allergy. The pollen of Prosopis spicigera is the most important cause of pollinosis in Kuwait (Wilkinson, I964; A. W. Frankland, personal communication). As mentioned earlier, over I0,000 trees of this species have been introduced into the area of Ahmadi and many more planted in Kuwait town. The houses are surrounded by the trees which were planted for shade; pollen clumps are shed in the vicinity and settle quickly but high concentrations occur beneath the trees. In future planting programmes the importance of this tree as a cause of inhalant allergy should be noted, and until such time as they can be successively replaced without loss of amenity, allergic people should be housed to the N.W. of the planted area and instructed to avoid the trees as much as possible in the April/May and November/ December flowering periods.

In Wilkinson's (1964) study, the 'gravity slide' appears to have overestimated the numerical importance of grass and other pollens relative to those of the Chenopodiaceae, a family not only common in desert floras but well adapted to anemophily. Dr A. W. Frankland (personal communication) finds that atopic patients normally resident in Arabia usually show skin sensitivity to extracts of pollen from Chenopodium album Linn. Hence the chenopod pollen to which these patients are commonly exposed is antigenically similar to the English grown C. album. At Ahmadi, chenopod pollen concentrations averaged over 50 grains $/ \mathrm{m}^{3}$ for 3 weeks in September and October; such concentrations are comparable with those for grass pollen in England in June and July, and experience has shown that concentrations of grass pollen of 50 grains $/ \mathrm{m}^{\mathbf{3}}$ in Central London almost invariably produced hay fever in patients clinically sensitive to grass pollen (Frankland and Davies, unpublished observations). Chenopod concentrations in Central London are rarely as high as 10 grains $/ \mathrm{m}^{\mathbf{3}}$ and it is an uncommon cause of pollinosis in England. Wilkinson (1964) reported that many hay fever subjects at Ahmadi were hypersensitive to the Chenopodiaceae and Bermuda grass in addition to Prosopis. Extracts of pollen from Salsola baryosma and other chenopods indigenous to the area, such as Anabasis articulata (Forsk.) Moq. and Haloxylon salicornicum (Moq.) Boiss, which are common in the westerly parts of Kuwait (Dickson, 1955), have not yet been obtained. From the aerobiological evidence, grass pollen is unlikely to be an important cause of pollinosis in Kuwait since it was only occasionally trapped. The maximum concentration recorded was only Io grains $/ \mathrm{m}^{3}$ and in London where $0.5 \%$ of the population experience grass pollinosis in the June/July season, daily concentrations of hundreds of grains $/ \mathrm{m} .{ }^{3}$ are recorded, and average concentrations during the seasons from 1961 to 1968 ranged between 50 and 130 grains $/ \mathrm{m}^{3}$

Hypersensitivity to fungal spores does not yet appear to have become a serious problem among the population at Ahmadi although Dr. D. W. Frankland (personal communication) reported that positive skin (prick) reactions to Aspergillus niger are not uncommon in allergic patients from this area, and Wilkinson (1964) reported that many patients complained that their symptoms were worse at night indoors. The possibility of mould development in the dust that accumulates in air cooling ducts has been mentioned.

Outdoors the concentration of Cladosporium spores reached a maximum weekly average of $1250 / \mathrm{m}^{3}$ and the highest daily concentration was 1750 . Frankland \& Davies (1965) report that, in patients with hypersensitivity to this spore, symptoms are precipitated when mean daily concentrations rise to 3000 or more $/ \mathrm{m} .^{3}$ From this 
evidence it needs but a twofold increase in the concentrations of Cladosporium in the air of Kuwait for it to become clinically significant in the atopic population.

Since this survey was undertaken in 1962-3, the planting programmes have been continued, especially in the vicinity of the state capital, Kuwait. As the areas of vegetative cover are extended, the fungal flora will increase and inhalant allergy due to fungal spores will inevitably become more common. Periodic surveys of the air spora would appear to be desirable so that in the light of the knowledge obtained, the planned ecological succession may be from time to time modified in the interest of the people prone to allergic diseases.

I should like to thank Dr A. W. Frankland and Dr John Brebner for interesting me in the problem, and Kuwait Oil Company for the operation of the Hirst trap at Ahmadi.

\section{REFERENCES}

BLATtER, E. (1919). Records of the Botanical Survey of India, 8, Flora Arabica i. Calcutta: Superintendent of Government printing.

DAVIES, R. R. (1959). Detachment of conidia by cloud droplets. Nature, Lond. 183, 1695.

DAVIES, R. R. (1960). Viable moulds in house dust. Trans. Br. mycol. Soc. 43, 617.

DAVIES, R. R., DENNY, M. J. \& Newton, L. M. (1953). A comparison between the summer and autumn air-sporas at London and Liverpool. Acta allerg. 18, 131 .

Dickson, V. (1955). The Wild Flowers of Kuwait and Bahrain. London: Allen and Unwin.

Dworin, M. (1967). Allergy in the Sonoran desert. Int. Congr. Allerg., Excerpta Medica 144, 41.

Frankiand, A. W. \& DaVIES, R. R. (1965). Allergie aux spores de moisissures en Angleterre. $L e$ Poumon et le Coeur I, II.

Gregory, P. H. \& Stedman, O. J. (1953). Deposition of airborne Lycopodium spores on plane surfaces. Ann. appl. Biol. 40, 651 .

HIRST, J. M. (1952). An automatic volumetric spore trap. Ann. appl. Biol. 39, 257.

HIRST, J. M. \& Stedman, O. J. (1963). Dry liberation of fungus spores by raindrops. J. gen. Microbiol. 33, 335.

LAST, F. T. (1955). The seasonal incidence of Sporobolomyces on cereal leaves. Trans. Br. mycol. Soc. 38, 221 .

PADY, S. M. \& KAPICA, L. (1953). Air-borne fungi in the Arctic and other parts of Canada. Can. J. Bot. 3r, 309.

Perkins, W. A. (1957). The rotorod sampler. Semi-ann. Rep. Aerosol Lab. Stanford Univ. CML. 186, I; quoted by Gregory, P. H. \& Lacey, M. E. (1964). Trans. Br. mycol. Soc. 47, 25.

PolunIN, N. (1955). Arctic aeropalynology. Spora observed on sticky slides exposed in various regions in 1950. Can. J. Bot. 33, 401 .

ROTEM, J. (1965). Sand and dust storms as factors leading to Alternaria blight epidemics on potatoes and tomatoes. Agric. Meteorology 2, 281.

WikINSON, W. M. (1964). Development of allergy in the desert. J. trop. Med. Hyg. 67, I6. 